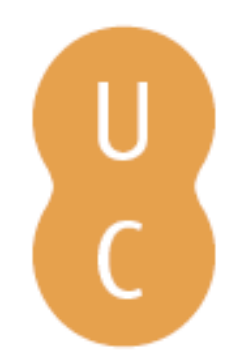

\title{
pompalina
}

\section{Os factos no casamento e o direito na união de facto: breves observações}
Autor(es):
Coelho, Francisco Brito Pereira
Publicado por: Imprensa da Universidade de Coimbra
URL
persistente:
URI:http://hdl.handle.net/10316.2/38881
DOI:
DOI:http://dx.doi.org/10.14195/978-989-26-1113-6_3
Accessed : $\quad$ 26-Apr-2023 13:44:05

A navegação consulta e descarregamento dos títulos inseridos nas Bibliotecas Digitais UC Digitalis, UC Pombalina e UC Impactum, pressupõem a aceitação plena e sem reservas dos Termos e Condições de Uso destas Bibliotecas Digitais, disponíveis em https://digitalis.uc.pt/pt-pt/termos.

Conforme exposto nos referidos Termos e Condições de Uso, o descarregamento de títulos de acesso restrito requer uma licença válida de autorização devendo o utilizador aceder ao(s) documento(s) a partir de um endereço de IP da instituição detentora da supramencionada licença.

Ao utilizador é apenas permitido o descarregamento para uso pessoal, pelo que o emprego do(s) título(s) descarregado(s) para outro fim, designadamente comercial, carece de autorização do respetivo autor ou editor da obra.

Na medida em que todas as obras da UC Digitalis se encontram protegidas pelo Código do Direito de Autor e Direitos Conexos e demais legislação aplicável, toda a cópia, parcial ou total, deste documento, nos casos em que é legalmente admitida, deverá conter ou fazer-se acompanhar por este aviso.

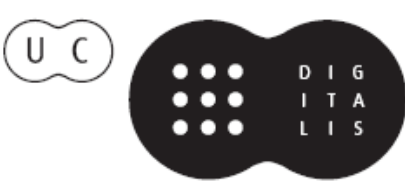




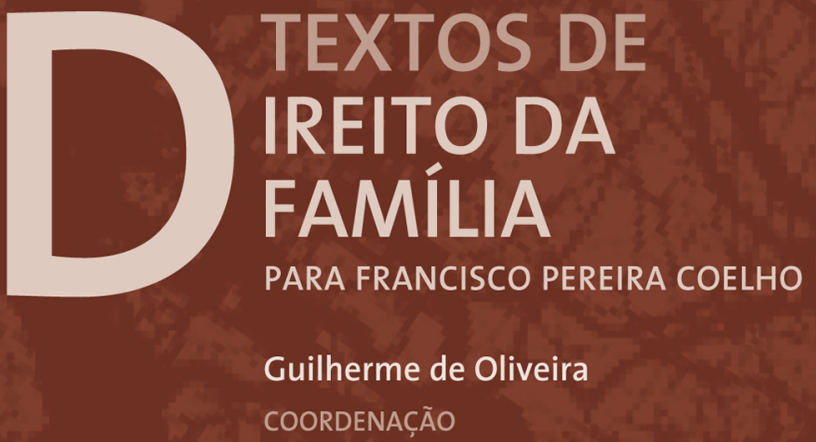




\section{OS FACTOS NO CASAMENTO E O DIREITO NA UNI ÃO DE FACTO: BREVES OBSERVAÇÕ ES}

Francisco Brito Pereira Coelbo Professor Auxiliar da Faculdade de Direito da Universidade de Coimbra

1. A caracterização da união de facto como o puro facto da convivência em condições análogas às dos cônjuges - caracterização

que não encerra especiais dificuldades ${ }^{1}$ e, aliás, é explicitamente acolhida na lei ${ }^{2}$ - permite estabelecer, de modo claro, a sua distinção em face do casamento.

De acordo com a perspectiva mais frequentemente seguida ${ }^{3}$, a qual se apoia aliás nas próprias definições legais dos dois institutos, o casamento, como se sabe, constitui um contrato - por conseguinte, um compromisso jurídico firmado entre os sujeitos, que se vinculam um em face do outro (seja qual for o exacto objecto e a força efectiva

1 Apesar de alguns autores (v. C. PAMPlona CORTE-REAL/J. SILVA PEREIRA, Direito da Família, Tópicos para uma reflexão crítica, $2^{\mathrm{a}}$ ed., Lisboa, 2011, p. 150) confessarem "uma quase impotência técnica" para se obter o correcto enquadramento jurídico do instituto - isto, naturalmente, em face do quadro de efeitos que a lei associava à união de facto (o texto que citamos é anterior à Lei $n^{\circ}$ 23/2010, de 30 de Agosto, mas seguramente que a dita "impotência técnica", na perspectiva adoptada pelos autores, se manteria após as alterações introduzidas por aquele diploma).

2 Cfr. o art. $1^{\circ}, n^{\circ} 2$, da Lei $n^{\circ} 7 / 2001$, de 11 de Maio, com a redacção dada pela Lei $n^{\circ} 23 / 2010$.

3 Assim, entre outros, F. PEREIRA COElho/Guilherme DE Oliveira, Curso de Direito da Família, I, Coimbra, 2008, ps. 52 ss. 
dessa vinculação). A "plena comunhão de vida" que os cônjuges instituem entre si, e os comportamentos em que tal comunhão de vida se exprime, correspondem, no quadro do casamento, à execução ou cumprimento de deveres contratualmente assumidos ${ }^{4}$. Diversamente, a união de facto consiste apenas na prática (continuada) de tais comportamentos - os comportamentos associados à referida "comunhão de vida" - sem que tais comportamentos correspondam à execução ou cumprimento de qualquer obrigação contratual - tratando-se pois, nesta conformidade, de uma comunhão de vida livremente exercida, fora do quadro vinculativo de um contrato.

Dir-se-á, nesta sequência, que a união de facto de algum modo se aproxima de uma figura geral, bem conhecida da doutrina geral do acto (e do negócio) jurídico, que é a do "simples acordo": os sujeitos pretendem a produção de efeitos práticos - pretendem a produção dos efeitos práticos correspondentes à relação entre cônjuges, ou a uma relação análoga à que os cônjuges desenvolvem -, mas não pretendem que tais efeitos práticos sejam tutelados ou garantidos pelo direito. Das duas vontades em que se analisa o conteúdo declarativo no negócio jurídico, de acordo com a designada "teoria dos efeitos prático-jurídicos" - - a vontade de produção de determinados efeitos práticos, e a vontade de que esses efeitos sejam tutelados pelo direito, e nessa medida sejam portanto, também, efeitos "jurídicos" -, está apenas presente, pois, a primeira: a vontade de produção

\footnotetext{
${ }^{4}$ Neste sentido se dirá que os deveres conjugais fixados no art. $1672^{\circ}$ do Código Civil consubstanciam o desenvolvimento ou a densificação do "dever-quadro" de constituição de uma "plena comunhão de vida", o qual se acha previsto na própria noção legal de casamento do art. $1577^{\circ}$.

5 A comunhão (continuada) de "leito, mesa e habitação", ou a convivência em condições análogas às dos cônjuges.

$6 \mathrm{Ou}$ "acordo de cavalheiros" ("gentlemen's agreement"). V., sobre a figura, C. MOTA PINTO, Teoria Geral do Direito Civil, Coimbra, 2005, p. 382.

7 V. o nosso Contratos complexos e complexos contratuais, Coimbra, 2014, p. 91 e ss, e ainda C. MOTA PINTO, cit., p. 381-2, e P. MOTA PINTO, Declaração tácita e comportamento concludente no negócio jurídico, Coimbra, 1995, p. 45 e ss.
} 
de efeitos práticos, que todavia não querem que sejam alcançados por via do direito. As partes excluiriam logo, pois, a relevância jurídica do compromisso, colocando-o assim fora da órbita ou da tutela do direito ${ }^{8}$ - o compromisso firmado e os comportamentos em que ele se concretizaria permaneceriam, por conseguinte, no puro domínio dos factos.

Simplesmente, como é fácil observar, e por um lado, tal consideração da união de facto como um "simples acordo" não faz luz, verdadeiramente, sobre a sua natureza: desloca o fulcro da união de facto para um (suposto) acordo inicial, e portanto para um momento declarativo inicial, quando o que é realmente constitutivo da união de facto é, sim, a (posterior) efectiva convivência em condições análogas às dos cônjuges, e por conseguinte o (posterior) "momento executivo" traduzido na prática dos actos correspondentes à efectiva execução das obrigações que normalmente impendem sobre os cônjuges.

E, por outro lado, afigura-se que a união de facto, definida como a definimos, tem uma extensão afinal maior que aquela que resulta das considerações precedentes. Também é união de facto, na realidade, a relação convivencial procedente de um casamento inexistente ou inválido. Nestas hipóteses o casamento também não teria vinculatividade jurídica (ressalvada a eventual produção de

\footnotetext{
8 Observe-se que, curiosamente, já foi questionada a própria possibilidade de os sujeitos excluírem a juridicidade naqueles negócios - como seria justamente o caso do casamento - disciplinados "na sua essência" por normas imperativas (v., neste sentido, Cariota-Ferrara, referido no nosso Contratos complexos, cit., p. 99). Entendemos, todavia (tal como expomos em Contratos complexos, cit., ps. 116-7), que nem mesmo em tais contratos se encontrará à partida proibida aquela convenção de exclusão. Tudo estará em saber se essas normas de ordem pública contendem com a própria atribuição de efeitos jurídicos ao compromisso firmado, e não apenas com o regime e efeitos do contrato (no caso de lhe serem atribuídos esses efeitos jurídicos). Por outras palavras, não se trata tanto de saber se tais normas de ordem pública afectam a liberdade de fixação do conteúdo contratual (e será este o caso do casamento), mas sobretudo de saber se essas normas afectam a própria liberdade de contratação, por isso que só esta contende com o problema da (in)admissibilidade da referida convenção de exclusão da eficácia jurídica.
} 
efeitos putativos9) - mas agora não porque os sujeitos não queiram vincular-se juridicamente, mas tão-somente em consequência da ineficácia do casamento. Diremos que, neste caso, a união de facto, longe de consubstanciar um "simples acordo" ou "acordo de cavalheiros", apresentaria maior analogia com a figura, também conhecida da doutrina geral das obrigações, das "relações contratuais de facto" 10 : nestas como naquela, registar-se-iam os mesmos comportamentos materiais correspondentes à execução de obrigações contratuais típicas (no caso, das obrigações contratuais próprias do casamento), sem que, todavia, houvesse sido celebrado um qualquer contrato (ou um contrato existente e válido) entre os sujeitos - sem, pois, a presença do elemento "declarativo" (ou de um elemento declarativo existente e válido) inicial a que nos referimos. Em relação a este grupo de hipóteses - mas apenas em relação a ele, e sobretudo quando esteja em causa a inexistência ou invalidade resultantes de um vício formal - tem cabimento a afirmação, feita por alguns autores ${ }^{11}$, de que a união de facto se

9 Nos termos dos arts. $1647^{\circ}$ e $1648^{\circ}$ do Código Civil.

10 Excogitada, como é sabido, por Haupt (v., sobre o tema, entre outros, o apontamento de L. MENEZES LEITÃo, Direito das Obrigações, I, $7^{\mathrm{a}}$ ed., Coimbra, 2008 , p. 505 e ss.), a categoria das relações contratuais de facto tinha por propósito fundamental, em termos práticos, estender a tais relações a imposição de determinadas obrigações contratuais ainda que, como se disse, não se divisasse propriamente um contrato celebrado (ou validamente celebrado) entre os sujeitos. Ora, e independentemente da óbvia discutibilidade da categoria enquanto categoria autónoma (v., neste sentido, L. MENEZES LEITÃO, cit., p. 511 e ss.) - discutibilidade que, aliás, explicará a actual decadência da doutrina das relações contratuais de facto, tanto entre nós como no próprio espaço jurídico de onde ela provém -, o que devemos observar é que, apesar da aparente analogia com a união de facto, aquele propósito fundamental não tem aqui cabimento. Efectivamente, se no âmbito das relações contratuais de facto se pressupõe que determinadas obrigações que seriam devidas no quadro de um normal contrato ainda não foram cumpridas - o referido propósito consiste precisamente em impor a uma das partes o cumprimento de tais obrigações -, já no âmbito da união de facto se pressupõe, pelo contrário, que as obrigações matrimoniais (já) são normalmente cumpridas, sendo esse, aliás, um pressuposto que resulta do próprio conceito de união de facto.

11 Assim, Guilherme De Oliveira, Notas sobre a Lei $n^{\circ}$ 23/2010, de 30 de Agosto (Alteração à Lei das Uniões de Facto), in "Jus Familiae - Revista Portuguesa de 
apresentaria, de algum modo, como uma espécie de casamento informal.

Diremos, pois, que não existe afinal unidade na figura da união de facto: à diversidade de motivos ou circunstâncias que podem levar à união de facto corresponde, se bem virmos, uma diversidade no respectivo enquadramento jurídico. E a esta diversidade no seu enquadramento jurídico podem achar-se associados, também, diversos âmbitos de protecção ou reconhecimento jurídico ${ }^{12}$.

2. Seja como for, a referida diferença fundamental entre o casamento e qualquer forma de união de facto - o casamento como um compromisso jurídico gerador de obrigações, a união de facto como o puro facto da convivência em condições análogas às dos cônjuges, sem o intento de estabelecer um vínculo jurídico ou sem a possibilidade de esse vínculo se estabelecer -, diferença que, como vimos, vem sendo evidenciada pela generalidade dos autores, não impede que, como é fácil perceber, esse puro facto que é a união de facto possa produzir efeitos jurídicos ${ }^{13}$.

Direito da Família", Ano 7, $\mathrm{n}^{\circ}$ 14, Coimbra, Julho/Dezembro de 2010, p. 140 (ainda que colocando-se sobretudo numa perspectiva de jure condendo), e C. PAMPLONA CORTE-REAL/J. SILVA PEREIRA, cit., p. 153.

12 Designadamente, se for celebrado casamento com impedimento dirimente (sendo por isso o casamento inválido), e havendo uma "união de facto" subsequente, naturalmente que não poderão aplicar-se-lhe os efeitos protectivos estabelecidos para a união de facto - a não ser através dos eventuais efeitos putativos do casamento, que nesse caso absorverão aqueles efeitos protectivos. Cabe aliás observar que, tal como a invalidade do casamento não impede a produção de efeitos putativos, se se verificarem os seus pressupostos, assim também a "invalidade" da união de facto - quer dizer, a sua "ineficácia" em consequência das circunstâncias previstas no art. 2. ${ }^{\circ}$ da Lei n. $7 / 2001$ - não deverá impedir que operem os respectivos e feitos no caso de se registarem, em relação à união de facto, e feitas as necessárias adaptações, os pressupostos de produção de efeitos putativos (os quais se reportam fundamentalmente à boa fé dos sujeitos).

13 Pretendendo, todavia, que haveria um "contra-senso" legal na consideração da união de facto (pela própria lei) como uma "realidade fáctica" quando simultaneamente lhe são atribuídos, pela mesma lei, efeitos jurídicos extensos e signifcativos, v. C. PAmplona CORTE-Real/J. Silva Pereira, cit., p. 147. Como sublinhamos no texto, não vemos porém que haja aí qualquer "contra-senso": sendo um acto de na- 
Efectivamente, quando se diz que a união de facto é apenas um facto, o que se pretende dizer é que não tem a natureza de negócio jurídico. Não poderá por isso produzir efeitos negociais ou "directos" como aqueles a que, radicando directamente na vontade dos sujeitos nessa direcção, tende um comum negócio jurídico - como aqueles a que, precisamente, tenderia o casamento ${ }^{14}$.

Mas naturalmente que a lei pode determinar a produção de efeitos de outra natureza - efeitos, pois, indirectos ou legais -, tendo em consideração o facto de haver uma comunhão de vida prolongada entre duas pessoas e o eventual interesse protectivo (ou um interesse de outro tipo) que essa convivência lhe possa merecer ${ }^{15}$. Nesta medida diremos que a união de facto, se não é ou não procede de um negócio jurídico, por lhe faltar a referida vontade de vinculação

tureza não negocial, a união de facto não deixa de poder produzir efeitos jurídicos (que, como é óbvio, o ordenamento jurídico pode associar-lhe), sendo pois, nessa medida, um acto jurídico.

${ }^{14} \mathrm{O}$ facto de os efeitos principais do casamento terem essa natureza de efeitos negociais, que portanto assentam numa vontade (negocial) nessa direcção, não impede que a lei possa intervir imperativamente nesse campo, impondo determinadas consequências ou uma sua particular configuração. É precisamente o que sucede com os deveres pessoais dos cônjuges, os quais, representando deveres impostos reciprocamente aos cônjuges, de modo imperativo - isto pelo menos numa consideração literal de tais deveres, e abstraindo portanto da sua flexibilidade no momento da sua execução, ou da própria discutibilidade da sua caracterização como "deveres" tendo em conta o quadro de consequências que hoje a lei associa ao seu incumprimento -, não deixam todavia de ser os efeitos negociais a que directamente, e de modo principal, se dirigem as declarações de vontade dos nubentes.

15 Rejeitamos pois aqui o argumento de que, como na união de facto os companheiros não assumiriam deveres, também não poderiam beneficiar dos diversos direitos que a lei concede às pessoas casadas. Tal argumento, que julgamos historicamente datado (supomos mesmo que hoje já não será subscrito pelos próprios autores que o usaram), assenta numa espécie de "sinalagma" que efectivamente não existe: os deveres conjugais têm o seu correspectivo "sinalagmático" nos correspondentes direitos do outro cônjuge (o sinalagma existe pois na relação interna entre os cônjuges), não nos benefícios que a lei concede, por razões várias, àqueles que estão ou estiveram casados. Sobre essa distinção entre o "estatuto privado" e o "estatuto social", no sentido de que a um "estatuto privado" de ausência de deveres conjugais não poderia corresponder um "estatuto social" de pretensão de obtenção dos benefícios reservados aos casados, v. RITA L. XAVIER, Novas sobre a União de Facto "more uxorio" em Portugal, in "AAVV, Estudos dedicados ao Prof. Doutor Mário Júlio Almeida Costa", Lisboa, 2002, ps. 1398 e ss. 
no plano jurídico, ou em consequência da sua ineficácia, não deixa de constituir um simples acto jurídico, um acto produtor de efeitos jurídicos diversos, de maior ou menor extensão ou significado - à união de facto não corresponde pois um qualquer estatuto negocial (um qualquer quadro de efeitos negociais), mas apenas um estatuto legal $^{16}$. Já o casamento, constituindo como vimos um negócio jurídico, tendente à produção de certos efeitos que os sujeitos pretendem sejam tutelados pelo direito, tem o seu próprio estatuto negocial, correspondente ao quadro de efeitos essenciais visados normalmente pelos nubentes; tal como terá o seu estatuto legal, correspondente ao largo conjunto de efeitos não essenciais (laterais, indirectos ou eventuais) que o ordenamento jurídico associa ao estado matrimonial.

3. Estas, pois - assim descritas de modo sumário -, a analogia e a diferença entre a união de facto e o casamento.

Ora, registadas tal analogia e tal diferença, torna-se evidente que, no presente quadro regulativo, não pode, por um lado, ser recusada liminarmente a possibilidade de aplicação, à união de facto, de normas pertencentes ao regime do casamento, a pretexto de que o casamento representaria um compromisso constitutivo de deveres jurídicos (e outros efeitos juridicamente tutelados) ${ }^{17}$, e portanto nun- $^{-}$ ca haveria uma analogia, em tal sentido. Na realidade, desde que se trate de efeitos indirectos ou legais do casamento, e de efeitos fundados na simples existência de uma comunhão de vida - independentemente, pois, de esta comunhão representar o cumprimento de um dever jurídico procedente de um contrato -, é óbvio que pode

16 Porque os efeitos da união de facto são apenas, como dizemos no texto, seus efeitos legais ou "indirectos".

${ }^{17} \mathrm{E}$ dotado de uma determinada garantia jurídica de durabilidade - o que se traduziria quer na proibição de aposição de condição ou termo resolutivos, quer sobretudo num (ainda) relativamente apertado quadro de restrições às possibilidades de cessação do casamento. 
haver analogia relevante, a qual resultará aliás da própria definição da união de facto como a comunhão de vida em condições análogas às do casamento ${ }^{18}$.

Por outro lado, também não pode, no actual quadro legislativo, ser liminarmente afirmada uma genérica aplicação analógica de todas as normas do casamento ${ }^{19}$. Além de tal aplicação só poder abranger, como parece evidente, os referidos efeitos legais ou indirectos do casamento ${ }^{20}$, sempre teria de se apurar, caso a caso, quais os interesses em presença e a ratio da norma eventualmente aplicável - pois só assim se pode fundar uma aplicação em via analógica. $\mathrm{E}$, de qualquer modo, não pode deixar de ter-se em conta que a nossa lei parece ter tido o intuito de fixar um quadro limitado de efeitos - o quadro de efeitos constante da Lei $\mathrm{n}^{\circ} 7 / 2001$-, pelo que

18 Um exemplo conhecido desta possível aplicação analógica de normas do casamento, encontramo-lo na (possível) responsabilização de ambos os unidos por dívidas contraídas para acorrer aos encargos da vida familiar. Sobre este ponto - e, em particular, sobre a inclusão no Decreto da Assembleia da República n ${ }^{\circ} 349 / \mathrm{X}$, de 2009, de uma disposição que previa precisamente a comunicabilidade de tais dívidas, disposição que todavia acabou por não passar para o texto da Lei $n^{\circ}$ 23/2010, de 30 de Agosto -, v. Guilherme De Oliveira, Notas, cit., p. 150 ss. e F. Pereira COELho/GUilherme De Oliveira, Curso, cit., p. 75-6 e 409. Observamos, porém, que não nos parece que a referida analogia se funde na aparência de casamento que existiria na união de facto, aparência que justificaria que terceiros (credores) merecessem a mesma protecção que a lei lhes dispensa quando o sujeito que contrai a dívida é casado (afirmando essa "confiança" na "aparência de vida matrimonial", v. os autores atrás citados). Além de não haver propriamente uma "aparência de casamento" - pelo menos, não mais que uma aparência de... união de facto -, e de não ser crível que o credor investigue o estado civil do devedor, supomos que o que funda o art. $1691^{\circ}, \mathrm{n}^{\circ} 1$, al. b), são não tanto razões "externas" como essas, antes razões "internas" relacionadas com a existência de uma prática de vida em comum, e portanto com a razoabilidade de, sendo a dívida contraída para acorrer aos encargos relativos a essa vida em comum, ambos os sujeitos deverem responder por essas dívidas.

19 No sentido de uma ampla aplicação analógica das normas do casamento incluindo-se nessa aplicação analógica, note-se, os arts. $2133^{\circ}$ e $2157^{\circ}$ do Código Civil (ou seja, a extensão ao unido de facto sobrevivo da qualidade de herdeiro legítimo e legitimário!) - v. C. PAMPLONA CORTE-REAL/J. SILVA PEREIRA, cit., p. 153 ss.

${ }^{20}$ Pois que julgamos que os seus efeitos directos ou negociais ninguém pretenderia aplicar analogicamente à união de facto. Mas deve registar-se que tal distinção entre efeitos negociais e efeitos legais, se é clara em abstracto, pode não ser fácil de fazer em concreto. 
se afigura que tal intuito impede uma aplicação analógica irrestrita das normas do casamento.

4. Seja como for, parece que, sobretudo com os últimos desenvolvimentos legislativos registados quer na regulação da união de facto (com as alterações à Lei $\mathrm{n}^{\circ} 7 / 2001$ introduzidas pela Lei $\mathrm{n}^{\circ}$ 23/2010, de 30 de Agosto), quer, fundamentalmente, na regulação do casamento (em consequência da profunda reforma operada pela Lei $n^{\circ} 61 / 2008$, de 31 de Outubro), a referida diferença entre os dois institutos - a diferença, recorde-se, traduzida em não haver na união de facto uma vontade de vinculação no plano jurídico, e por conseguinte a comunhão de vida praticada entre os unidos não corresponder ao cumprimento de quaisquer deveres conjugais - ficou consideravelmente esbatida. Podendo mesmo interrogar-nos se, tendo em conta tais desenvolvimentos, permanece afinal qualquer diferença substancial entre os dois institutos.

Senão vejamos.

a) No que se reporta ao regime do casamento, vem-se assistindo, em primeiro lugar - num movimento que, como é sabido, é muito anterior à Reforma de 2008 -, a uma progressiva desregulação ou deslegalização do casamento. O direito afasta-se ou desinteressa-se cada vez mais da regulação do casamento ${ }^{21}$, sobretudo da sua regulação em termos imperativos. E isto não apenas no campo dos efeitos patrimoniais do casamento, em que já se registava uma larga margem de autonomia dos cônjuges ${ }^{22}$, mas sobretudo no dos

\footnotetext{
${ }^{21}$ Fala-se correntemente, a este propósito, de uma retirada ou recuo do direito ("retrait du droit").

22 Presente, sobretudo, na liberdade de selecção do regime de bens (art. $1698^{\circ}$ do Código Civil). Mas é óbvio que permanecem limites à autonomia patrimonial dos cônjuges com algum significado, como sucede com a subsistência de um princípio como o da imutabilidade dos regimes de bens, ou com a subsistência de um regime patrimonial "primário" (fundamentalmente no que toca ao regime de administração e disposição dos bens do casal, e ao regime da responsabilidade por dívidas) em que é explicitamente proclamada uma regra de imperatividade (art. $1699^{\circ}$ do Código
} 
seus efeitos pessoais. Aqui, o conjunto de disposições contidas no Código Civil limita-se a fixar os "deveres pessoais" dos cônjuges um em face do outro e pouco mais; e, se tais deveres devem ser lidos como impostos imperativamente, é também verdade que, como há muito se vem entendendo - e corresponde mesmo a uma evidência imposta pela especialidade da relação interconjugal -, os modos de execução de tais deveres conjugais não obedecem a um padrão único, podendo variar em função de uma multiplicidade de factores (como a própria personalidade dos cônjuges, o seu modo de relacionamento, a sua capacidade de tolerância, etc.). Aliás, ao mesmo tempo que se desinteressa da regulação (sobretudo imperativa) do casamento, o direito permite simultaneamente que sejam os cônjuges a proceder eles mesmos à conclusão de "acordos sobre a orientação da vida em comum"23 - neste campo, pois, dir-se-á que cada vez mais a "auto-regulação" convencional ocupa o espaço deixado pela hetero-regulação legal.

b) Em segundo lugar, e em conexão com esta ideia de progressiva desregulação do casamento, deparamos com o progressivo afrouxamento dos deveres conjugais. É verdade que, como já dissemos, sempre se reconheceu que tais deveres apresentariam uma particular

\footnotetext{
Civil). Não tratamos todavia, no presente contexto, nem da possível incongruência entre aquela autonomia e estes constrangimentos imperativos, nem da discutibilidade das razões em que é costume fundar estes limites imperativos - uma espécie de ordem pública matrimonial no campo patrimonial, ligada à tutela do interesse (patrimonial) de um dos cônjuges, putativamente mais débil, ou, porventura, à defesa de interesses de terceiros (designadamente credores).

23 Nos termos do art. $1671^{\circ}$. Julgamos a este propósito, porém, que o "acordo" a que se refere a disposição é mais o acordo pontualmente necessário para a tomada de cada decisão que integra a dita "vida em comum" do que propriamente um "grande acordo" que, no início da vigência do casamento, fixaria genericamente os quadros em que se moveria a vida comum dos cônjuges - é mais, neste sentido, diríamos, o acordo-autorização que o acordo-contrato. Ainda que se tratasse sempre de um contrato-quadro, dotado de um grau mais ligeiro de força vinculativa - pelo que se falará assim de um princípio de proibição de uma auto-regulação vinculativa estrita.
} 
flexibilidade no momento da sua concreta execução ${ }^{24}$. Mas é óbvio que, descontada essa - aliás evidente - flexibilidade, os deveres conjugais não deixaram de ser vistos verdadeiros deveres jurídicos, ao menos para alguns efeitos. Hoje, porém, após a Reforma de 2008, deve reconhecer-se que passou a ser difícil descortinar nos deveres conjugais qualquer marca característica de um verdadeiro e próprio dever jurídico, tanto no plano das consequências indemnizatórias do seu incumprimento como no das correspondentes consequências "resolutórias" (quer dizer, em matéria de divórcio).

No plano das possíveis consequências indemnizatórias do seu incumprimento, observe-se, aliás, que já há muito se entende - maioritariamente, entre nós, ao que julgamos saber - que a indemnizabilidade de danos não patrimoniais resultantes da violação de deveres conjugais não se aplicaria aos deveres ("relativos") especificamente conjugais ${ }^{25}$. A circunstância de a Reforma de 2008 até ter vindo introduzir explicitamente a possibilidade de reparação por danos não patrimoniais - diversamente do que sucedia na anterior versão do art. $1792^{\circ}$ do Código Civil, a qual se referia apenas aos danos não patrimoniais resultantes do divórcio -, mas tendo o cuidado de estabelecer que essa reparação se fará "nos termos gerais da responsabilidade civil”26, parece pois não significar, em rigor, um

${ }^{24}$ Havendo mesmo quem os degradasse a simples desenvolvimentos ou manifestações de um único e amplo dever conjugal de instituir e manter uma plena comunhão de vida (neste sentido, C. PAMPlONA CORTE-REAL/J. SILVA PEREIRA, cit., p. 130). Aliás, o BGB já não enumera qualquer elenco de deveres conjugais, limitando-se a impor genericamente (no $\S 1353$ ) que os cônjuges adoptem ...uma comunhão de vida (ainda que nas disposições subsequentes se disponha, de modo mais circunstanciado, acerca do modo de exercício da assistência entre cônjuges).

$25 \mathrm{Ou}$ seja, àqueles deveres que nascem com o casamento, correspondendo pois a direitos estritamente relativos - como sucede expressivamente com os deveres de coabitação e de fidelidade. É sobretudo esta irrelevância para efeitos indemnizatórios que dá corpo, como se sabe, à ideia da "fragilidade da garantia" dos direitos - pelo menos, destes direitos - familiares.

26 É certo que tal expressão, em si mesma, não tem forçosamente, de modo claro, esse preciso sentido - se é que tem algum sentido claro. Mas parece ter sido esse o propósito do legislador (v. GuIlHerme DE Oliveira, A nova lei do divórcio, in 
alargamento do âmbito da indemnizabilidade - antes, justamente, a consagração da doutrina já então maioritária, a qual, repete-se, já admitia o ressarcimento de danos não patrimoniais procedentes da violação de direitos absolutos ${ }^{27}$.

No plano dos possíveis efeitos - diríamos - "resolutórios"28 do incumprimento dos deveres conjugais, também hoje, após a Reforma de 2008, e como é sabido, a "violação culposa dos deveres conjugais" deixou de constituir fundamento de divórcio. É certo que pode dizer-se que, sendo agora irrelevante a culpa, a violação dos deveres conjugais continuaria ainda a relevar - agora, repete-se, independentemente de culpa - enquanto manifestação de uma possível ruptura definitiva do casamento, nos termos da al. d) do art. $1781^{\circ}$ do Código Civil. Com tal alcance se poderia portanto admitir que a "violação dos deveres conjugais" teria ainda importância prática, e que os "deveres conjugais" manteriam, pois, a este nível, a sua marca de verdadeiros "deveres". Tomando como referência o regime geral do incumprimento das obrigações, dir-se-ia que a lei desconsideraria a culpa no incumprimento, mas este conservaria o seu relevo no que se reportasse às consequências resolutórias do incumprimento não imputável ao devedor: tal como o incumprimento não imputável

\footnotetext{
"Jus Familiae - Revista Portuguesa de Direito da Família", Ano VII, n 13, Coimbra, 2010, p. 21): a remissão para os "termos gerais da responsabilidade civil" significará justamente que só se dará a reparação dos danos (não patrimoniais) sofridos por um dos cônjuges se tais danos forem indemnizáveis independentemente da sua situação de cônjuges - significará, pois, que essa reparação só será possível se se tratar de violação de direitos absolutos (porquanto se desconsidera a relação especificamente conjugal, e os direitos "relativos" nela inscritos)

27 Só podendo ser exercido o direito a indemnização, em princípio, com o divórcio - não antes disso. Note-se, de resto que a discussão era já travada antes de 2008, atento o silêncio da lei; mas hoje o ponto está, aparentemente, resolvido: a localização sistemática do art. $1792^{\circ}$ mostra tratar-se de um efeito do divórcio.

28 Quando dizemos "resolutórios" pretendemos referir-nos, como é óbvio, ao funcionamento do incumprimento dos deveres conjugais como causa ou fundamento do divórcio.
} 
ao devedor pode levar à resolução do contrato ${ }^{29}$, assim também a violação dos deveres conjugais, independentemente da culpa de qualquer dos cônjuges - culpa que, justamente, é hoje desconsiderada -, constitui, por essa via, fundamento de divórcio. Estamos em crer, porém, que este caminho parece insuficiente para que se possa falar de verdadeiros deveres conjugais, para este efeito: a "impossibilidade de cumprimento" não imputável ao devedor prevista nos arts. $790^{\circ}$ e ss do Código Civil é coisa diversa do voluntário incumprimento de deveres conjugais com desconsideração da culpa por parte da

29 Mas devemos observar que, no art. $795^{\circ}$ do Código Civil, a lei se confina a estabelecer que o credor fica "desobrigado" da contraprestação (liberação que aliás não é absoluta no caso de essa contraprestação já ter sido efectuada, pois que a lei se limita, em tal caso, a determinar a sua restituição nos termos do enriquecimento sem causa), não se pronunciando propriamente sobre a modalidade jurídica da extinção ou cessação dos efeitos negociais. Por outras palavras, a lei diz-nos o que sucede às obrigações ou às prestações contratuais, mas não nos esclarece sobre o que sucede ao próprio contrato (bilateral), que naturalmente vê cessarem ou extinguirem-se os seus efeitos em consequência daquela impossibilidade. Ora, uma primeira qualificação possível desta extinção ou cessação é a de resolução contratual: não apenas é esse o mecanismo tecnicamente adequado à vicisssitude aqui verificada (uma vicissitude relativa à execução contratual e surgida nessa execução, e que afecta o equilíbrio prestacional e a actuação do programa contratual por forma a que um dos sujeitos (pelo menos um) possa desvincular-se do contrato), como também é a própria lei a referir-se expressamente à "resolução" no art. $793^{\circ}$, a respeito da impossibilidade (igualmente não imputável) meramente parcial. É certo que a resolução resultante do art. $795^{\circ}$ se dá aqui como que "automaticamente", não estabelecendo a lei, de forma explícita, um direito que o credor/devedor possa ou não exercer, em função do seu interesse, como sucede nas hipóteses especiais previstas no art. $793^{\circ}, \mathrm{n}^{\circ} 2$ (caso em que o credor tem alternativa à resolução contratual, a qual será justamente a manutenção do contrato, confinada à parte possível da prestação e à respectiva contraprestação, conquanto aqui se deva também entender que em relação à outra parte da prestação, a parte "impossível", se dá igualmente uma resolução parcial) e no art. $801^{\circ}, \mathrm{n}^{\circ} 2$ (caso em que o credor pode ter ainda interesse em efectuar a prestação que lhe cabe, não procedendo pois à resolução do contrato). Será em razão da referida automaticidade que talvez seja preferível uma outra qualificação: tratar-se-ia antes de uma caducidade (neste sentido, L. MENEZES LEITÃo, Direito das obrigações, vol. II, Coimbra, 2008, p. 122), o que aliás se acha em conformidade com a expressa opção legislativa no caso de perda da coisa locada (art. $1051^{\circ}$, al. f), do Código Civil) e em outras hipóteses congéneres. Mas, além de que se trataria, em qualquer caso, de uma caducidade atípica (dados, designadamente, os efeitos tendencialmente ex tunc que lhe correspondem), o que é certo é que o que se acha em debate é um simples problema de construção/qualificação, o qual deve como tal ser desvalorizado. 
lei, como resulta do art. $1781^{\circ}$. Diríamos, nesta conformidade, que foi o próprio legislador a desvalorizar o casamento, que não é já um compromisso gerador de deveres que tenham de ser cumpridos, mas apenas um acordo que marca o início de uma comunhão de vida, no quadro da qual se espera que os cônjuges adoptem certo comportamento, que eles apenas adoptarão, evidentemente, enquanto durar essa comunhão. Teríamos portanto aqui uma categoria dogmática diversa do dever jurídico.

Concluímos, pois, que os deveres conjugais se acham hoje esvaziados das normais características de um dever jurídico. Das $f a-$ culdades em que se analisa o direito de crédito, no regime geral das obrigações - as faculdades de exigir o cumprimento, de promover a execução específica, de indemnização em caso de incumprimento, de uso da exceptio ou do commodum, de transmitir ou remitir o crédito, de resolver o contrato por incumprimento, etc. - poucas ou nenhumas estão presentes nos deveres (ou nos "créditos") conjugais. Por este lado também, por conseguinte, se esbate a distância entre o casamento e a união de facto. Na realidade, parece não ter sentido insistir-se na ideia de que, ao contrário da união de facto, o casamento representa um compromisso, em que os sujeitos são portadores de uma vontade de vinculação, quando o que sucede hoje é que o direito não lhes proporciona essa vinculação - aliás, não the proporciona nem permite essa vinculação.

c) Mas o referido esbatimento da distância entre o casamento e a união de facto podemos ainda registá-lo, em terceiro lugar, no que se reporta à cessação do casamento. Deixando de lado o divórcio por mútuo consentimento ${ }^{30}$, verificamos que ao anterior quadro de

30 No âmbito do qual, aliás, se vem assistindo a uma progressiva facilitação, quer no que toca à inexistência de qualquer prazo de duração efectiva do casamento, quer no que se refere ao procedimento a observar. Note-se, a este último propósito, que a nossa lei deixou de exigir, após a Reforma de 2008, e como condição para 
fundamentos de divórcio litigioso - que como se sabe incluía, ao lado da causa indeterminada subjectiva traduzida na violação culposa dos deveres conjugais, apenas três causas determinadas objectivas - sucedeu, após 2008, um quadro mais aberto que admite o divórcio com base na prova de qualquer facto que, independentemente da culpa de qualquer dos cônjuges, mostre a ruptura definitiva do casamento. Ao velho casamento tendencialmente perpétuo, sujeito a um controlo apertado da sua cessação - nas suas condições e nos seus procedimentos -, sucedeu pois um novo casamento, que poderá cessar sempre que se verifique a referida ruptura - que poderá cessar juridicamente, diríamos, sempre que (mas apenas se) houver cessado no plano dos factos.

Dir-se-á, nesta conformidade, que sob este aspecto a distância que separa hoje o casamento da união de facto ainda é alguma, mas é certamente mínima.

É óbvio haver ainda alguma diferença, quanto à "facilidade" da sua cessação, entre o casamento e a união de facto. Esta cessa, como é claro, quando cessar o facto da união - ou não se tratasse de uma realidade puramente fáctica -, facto que pode cessar pelo simples afastamento unilateral de um dos conviventes. Já o casamento permanece de algum modo um vínculo "formal", no sentido em que subsiste independentemente da subsistência de uma efectiva comunhão de vida ${ }^{31}$. E, diversamente do que sucede com a generalidade dos contratos patrimoniais duradouros - que podem cessar, em regra, por simples denúncia unilateral ad nutum -, para a cessação do casamento não basta essa declaração unilateral ad nutum, exigindo

o decretamento do divórcio por mútuo consentimento, que os cônjuges tenham chegado a acordo sobre as matérias "complementares" a que se refere o art. $1775^{\circ}$ do Código Civil.

${ }^{31}$ Registe-se, porém, que a separação de facto - que representa uma como que suspensão do casamento no plano dos factos - não é ignorada pela lei, que a dota de um estatuto próprio, para diversíssimos efeitos (os quais não vamos aqui tratar), constituindo pois também, em alguma medida, uma suspensão jurídica do casamento. 
a lei, como sabemos, a prova de factos objectivos ${ }^{32}$ que mostrem uma ruptura já verificada, nas condições do art. $1781^{\circ}$ do Código Civil.

Tal diferença, todavia, afigura-se mínima. Em primeiro lugar, verificada uma situação de ruptura, qualquer dos cônjuges pode deduzir um pedido de divórcio. E, em segundo lugar, deve reconhecer-se que, mesmo que não se haja ainda verificado uma situação de ruptura, qualquer dos cônjuges pode, se bem virmos, provocar de facto uma situação de ruptura (designadamente "forçando" uma separação de facto) se efectivamente quiser divorciar-se ${ }^{33}$. Observe-se, aliás, que, no próprio regime geral das obrigações, tende a considerar-se que a manifestação do propósito de não cumprir a obrigação, quando tal manifestação for inequívoca, consciente, definitiva e peremptória, deve ser equiparada a um incumprimento efectivo ${ }^{34}$.

Por este lado também, pois, perde sentido a ideia de que, no casamento, os sujeitos são portadores de uma vontade de vincu-

\footnotetext{
32 Não bastando, pois, que um dos cônjuges alegue, p. ex., que "já não ama o outro" ou deseja seguir "um diferente projecto de vida", nem, por maioria de razão, a manifestação de um simples propósito de provocar a ruptura. Vemos com alguma dificuldade, porém, que o julgador possa interferir, com o seu crivo pessoal, no juízo próprio de quem está dentro da relação, pelo que a avaliação da existência de uma ruptura definitiva do casamento deveria fazer-se sobretudo, estamos em crer, em função da óptica ou da avaliação do cônjuge.

33 Pergunta-se, pois, qual a lógica que preside a esta exigência de uma ruptura já verificada: se um dos cônjuges declara o propósito de criar uma situação de ruptura, não se entende porque a lei tem de esperar que essa ruptura se dê - não se entende porque a lei tem de esperar que, p. ex., o conflito se instale efectivamente no relacionamento conjugal. Pode pensar-se que o nosso legislador não terá tido a coragem de introduzir um sistema de divórcio "a pedido", no qual terá porventura pensado - mas da exposição de motivos que acompanha o projecto de lei que está na base da Lei $n^{\circ} 61 / 2008$ não se retira qualquer sugestão segura de que um sistema de divórcio "a pedido" haja sido efectivamente considerado.

${ }^{34} \mathrm{E}$ isto, precisamente, em consequência da absoluta inutilidade, em tal caso, de uma interpelação (ou do decurso do prazo convencionado) para constituir o devedor em mora, ou mesmo de uma interpelação admonitória para o credor poder resolver o contrato. V., sobre a recusa de cumprimento (ou declaração antecipada de não cumprimento), e a sua equiparação ao incumprimento efectivo (definitivo, possibilitando pois a resolução do contrato pelo credor, ou pelo menos provisório, com a constituição do devedor em mora), L. MENEZES LEITÃO, Direito das Obrigações, II, cit., p. 236.
} 
lação - agora neste plano da perdurabilidade do casamento -, porquanto o próprio direito acaba por não lhes proporcionar tal vinculação.

d) E se em matéria de efeitos pessoais o casamento se acha cada vez mais reduzido aos factos em que se traduz a comunhão de vida, praticada como for praticada e enquanto for praticada - sem a cobertura jurídica de uma estrita vinculação mediante a imposição de verdadeiros deveres jurídicos, e sem restrições efectivas à sua cessação logo que deflagrar uma situação de facto de ruptura da comunhão -, se em matéria de efeitos pessoais, dizíamos, as coisas são assim, também no domínio dos efeitos patrimoniais o casamento parece aproximar-se cada vez mais da união de facto, ainda que agora em moldes diversos.

No casamento, vale actualmente uma larguíssima margem de autonomia, expressa fundamentalmente, mas não apenas, na liberdade de celebração de convenções antenupciais e de fixação de regimes de bens ${ }^{35}$ - aliás, como é sabido, nas convenções antenupciais pode não apenas fixar-se o regime de bens mas também incluir-se outras estipulações convencionais, de carácter patrimonial ou até de carácter pessoal. É certo que a lei sujeita os cônjuges a uma densa e complexa teia de regras destinadas à disciplina do seu relacionamento patrimonial; e que, dentro desse conjunto de regras, permanecem alguns limites imperativos a tal autonomia ${ }^{36}$, fundados principalmente - digamo-lo de modo abreviado - em interesses de terceiros (fundamentalmente credores), ou no interesse de um dos cônjuges, presumivelmente mais débil, ou em geral na garantia de uma rela-

35 Art. $1698^{\circ}$ do Código Civil.

${ }^{36} \mathrm{~V}$., sobre o tema, a extensa e profunda análise monográfica de RITA L. XAVIER, Limites à autonomia privada na disciplina das relações patrimoniais entre os cônjuges, Coimbra, 2000. 
ção de efectiva igualdade entre os cônjuges ${ }^{37}$. Mas observe-se que alguns desses limites tendem a ser progressivamente abandonados pela generalidade das legislações ${ }^{38}$, enquanto outros, como é fácil demonstrar, se defrontam com incongruências no próprio quadro legislativo português actual 39 .

$\mathrm{Na}$ união de facto, por seu turno, parece valer um princípio geral de autonomia e informalidade ${ }^{40}$. Dir-se-á, aliás, que é isso mesmo que os conviventes se propõem - não apenas, como sabemos, no plano pessoal, mas também neste plano patrimonial.

Simplesmente, tal não impede, por um lado, que os sujeitos celebrem, se assim quiserem, um contrato (habitualmente designado de "contrato de coabitação") que funcionaria como um esquema regulador do seu relacionamento patrimonial, no âmbito do qual os conviventes, por via da estipulação de cláusulas sobre a pro-

${ }^{37} \mathrm{Em}$ obediência, de resto, ao princípio constitucional com esse mesmo sentido (art. $36^{\circ}, \mathrm{n}^{\circ} 3$, da Constituição)

38 Como sucede, expressivamente, com o princípio da imutabilidade das convenções antenupciais e dos regimes de bens. V., sobre o ponto, F. PEREIRA COELHO/ Guilherme De Oliveira, Curso, cit., p. 498-500.

39 P. ex., a lei estabelece a imperatividade do regime de administração dos bens do casal (art. $1699^{\circ}, \mathrm{n}^{\circ} 1$, al. c), do Código Civil), mas simultaneamente admite que um dos cônjuges, mediante mandato, tenha a administração exclusiva dos bens comuns ou dos bens próprios do outro (art. $1678^{\circ}, \mathrm{n}^{\circ} 1$, al. g)). E também parece haver alguma incongruência, em certos pontos, entre o regime da propriedade e o da responsabilidade por dívidas (pode p. ex. suceder que seja exclusiva a responsabilidade pela dívida do preço de um bem que, em propriedade, é comum a ambos - v., a tal respeito, o curto apontamento de C. PAMPLONA CORTE-REAL/J. SILVA PEREIRA, cit., p. 169) ou entre o regime da administração de bens e o da responsabilidade por dívidas (v. F. P. COelho/Guilherme DE Oliveira, Curso, cit., p. 406). De igual modo, se é verdade que é imperativa a regra da metade que preside à "estrutura" do património comum do casal e à respectiva partilha (art. $1730^{\circ}$ ), também é verdade que, através do recurso à via da sub-rogação real, os cônjuges podem, em muitos casos, logo no momento da aquisição do bem, adquiri-lo em compropriedade e aí fixar quotas diferentes para um e outro cônjuges (possibilidade, esta, não prevista explicitamente na lei, mas que resulta, de modo evidente, do art. $1723^{\circ}$, al. c), do Código Civil, em articulação com as regras gerais da compropriedade - v. F. P. COElHo/GUilherme DE Oliveira, Curso, cit., p. 518).

40 Sendo os problemas que se suscitem no âmbito do seu relacionamento patrimonial decididos caso a caso, de acordo com as regras gerais. 
priedade dos bens adquiridos após o início da união de facto ${ }^{41}$, ou sobre o modo de administração dos bens próprios de cada um ou dos adquiridos em compropriedade, ou sobre outras matérias afins, fixariam afinal um quadro regulativo equivalente ao que existe no

\footnotetext{
${ }^{41}$ Fazemos aqui duas observações.

Em primeiro lugar, repare-se que o Decreto $n^{\circ} 349 / X$ (que está na base da Lei $\mathrm{n}^{\circ} 23 / 2010$, de 30 de Agosto) previa expressamente, no seu art. $5^{\circ}-\mathrm{A}\left(\mathrm{n}^{\circ} 1\right)$, que os conviventes pudessem "estipular cláusulas sobre a propriedade dos bens adquiridos durante a união" - tal como previa, de igual modo, que se presumiria, independentemente da estipulação de tais cláusulas, a compropriedade dos móveis $\left(\mathrm{n}^{\circ} 2\right)$. A circunstância de tal disposição não haver passado para o articulado do texto legislativo não nos parece que signifique, de modo claro, uma proibição da estipulação daquelas cláusulas, ou o afastamento puro e simples do funcionamento da referida presunção. Por um lado, a estipulação de cláusulas "sobre a propriedade", como aliás de quaisquer outras cláusulas destinadas à (auto-)regulação das relações e interesses patrimoniais dos conviventes, constitui uma faculdade que resultaria já das regras gerais, no quadro da autonomia negocial normal (neste sentido, aliás, GUILHERME DE OliveirA, Notas, cit., p. 150). Por outro lado, a presunção de compropriedade dos móveis também resultará, estamos em crer, de uma analogia tirada da presunção do mesmo teor estabelecida no art. $1736^{\circ}, \mathrm{n}^{\circ} 2$, do Código Civil - supondo nós que neste caso a analogia é indiscutível, dado serem idênticas as circunstâncias "convivenciais" no âmbito das quais são adquiridos os bens móveis (se é normal que os móveis sejam adquiridos com o contributo de ambos os cônjuges, normal é também que o sejam se se tratar de simples unidos de facto) e dado o facto de o "regime de bens" vigente numa união de facto (na ausência, insistimos, de um contrato de coabitação que aponte em sentido diverso) ser exactamente equivalente ao regime (matrimonial) de separação de bens. E, ainda que não pudesse intervir aqui uma presunção legal, porque tirada por analogia e portanto não expressamente prevista na lei - argumento que, todavia, não subscrevemos -, sempre poderia funcionar uma presunção natural ou judicial (neste sentido, aliás, J. DUARTE PINHEIRO, O Direito da Família Contemporâneo, Lisboa, 2011, p. 732-733).

Em segundo lugar, devemos observar que, não tendo o contrato de coabitação o valor de "título legal" de deferimento da propriedade (como tem o casamento), podem suscitar-se dúvidas sobre o âmbito da eficácia de algumas das suas cláusulas - dúvidas que, aliás, vêm sido já de algum modo referenciadas pela (ainda escassa) literatura jurídica portuguesa sobre o tema (v., entre nós, C. PAMPLONA CORTE-REAl/J. Silva PEREIRA, cit., p. 171-3). Pergunta-se, designadamente, se o contrato de coabitação não estará confinado a uma eficácia puramente "interna" - propendendo nós a crer que a sua oponibilidade a terceiros estará efectivamente condicionada à sua inscrição no registo, o que, note-se, resultaria já das regras gerais e se acha prescrito para a própria convenção antenupcial (art. $1711^{\circ}$ do Código Civil). E pergunta-se, do mesmo modo, se nessa "convenção anteconvivencial" os companheiros podem fixar um regime de bens de comunhão idêntico ou análogo àqueles que tipicamente estão previstos para o casamento (é óbvio que poderiam sempre "pôr em compropriedade" quaisquer bens, nos termos gerais; mas a compropriedade, como é sabido, é uma forma de contitularidade de um bem em particular). Julgamos, também aqui, dever a resposta ser afirmativa: a circunstância
} 
casamento - se não na sua extensão pelo menos no seu objecto e nos seus propósitos. E muitas regras ou institutos aparentemente privativos do casamento - como porventura sucederá com a própria "comunhão" conjugal ${ }^{42}$ - poderão surgir afinal aplicados à união de facto por via da sua inclusão nesse "contrato de coabitação".

Por outro lado, apesar dessa aparência de uma total autonomia dos conviventes, julgamos que tal autonomia nunca será, em rigor, absoluta ou irrestrita: na realidade, achando-se constituída uma relação convivencial análoga à que se estabelece entre os cônjuges, é nosso juízo que haverá sempre um corpo mínimo de regras imperativas - designá-lo-íamos de "ordem pública convivencial" -, que naturalmente não é fácil identificar no presente contexto, mas às quais presidirá sobretudo uma ideia geral de preservação de uma relação igualitária entre os conviventes.

Por último, deve reconhecer-se que a larga maioria dos efeitos patrimoniais do casamento correspondem àquilo que denominámos de efeitos "indirectos" ou "legais" do casamento, não integrando pois o seu "estatuto negocial". Nada impede, por conseguinte, que as regras que estabelecem tais efeitos possam eventualmente aplicar-se analogicamente à união de facto 43 - desde que, como sabemos, se registe efectivamente analogia, tendo em conta a ratio de cada norma

\footnotetext{
de os regimes de comunhão estarem previstos como regimes matrimoniais não siginificará forçosamente que se trate de regimes exclusivamente matrimoniais, o que de resto, a ser aceite, corresponderia a um argumento puramente formal; e a consideração de que a propriedade colectiva (de que a comunhão conjugal é um exemplo) seria uma forma excepcional de contitularidade, sujeita a um princípio de legalidade estrito (neste sentido, reconhecemos, o ensinamento corrente entre nós: v. M. HenRiQue MESQuita, Direitos Reais, Coimbra, 1967, p. 235, C. MOTA PINTO, cit., p. 353, e ainda, com "alguma dúvida" embora, J. DUARTE PINHEIRO, cit., p. 726), também nos não parece que resulte directa e claramente dos dados da lei - nem do princípio da par conditio creditorum nem (mas aqui com algumas reservas) da regra do numerus clausus dos direitos reais fixada no art. $1306^{\circ}, \mathrm{n}^{\circ} 1$, do Código Civil.

$42 \mathrm{~V}$. nota anterior.

43 Inscreve-se aqui o debatido problema - a que já atrás fizemos referência - da eventual aplicação à união de facto do regime da responsabilidade comum pelas dívidas contraídas para acorrer aos encargos normais da vida familiar.
} 
potencialmente aplicável e o quadro de interesses em presença. Aliás, podemos mesmo afirmar que essa analogia foi reconhecida pela própria lei, numa escala razoável: as consequências (fundamentalmente de tipo "protectivo", sendo pois efeitos legais ou indirectos, como vimos dizendo) estabelecidas pela Lei $\mathrm{n}^{\circ} 7 / 2001$, sobretudo após as alterações introduzidas pela Lei $n^{\circ} 23 / 2010$, reportam-se justamente a mecanismos de protecção já fixados para o casamento, em relação aos quais se entendeu haver uma analogia suficiente para fundar a sua extensão à união de facto ${ }^{44}$ : os direitos do sobrevivo, ou dos ex-conviventes em caso de ruptura, respeitantes ao destino da casa de morada de família correspondem aproximadamente àqueles que a lei prevê para o casamento ${ }^{45}$, limitando-se mesmo a lei, em alguns casos, a pura e simplesmente remeter para o regime do casamento ${ }^{46}$; o direito de exigir alimentos da herança do falecido, constante do art. $2020^{\circ}$, corresponde também, de alguma forma, ao "apanágio do cônjuge sobrevivo" previsto no art. $2018^{\circ}$; os direitos às prestações sociais (e outras) de diversos tipos enumeradas nas várias alíneas do $\mathrm{n}^{\mathrm{o}} 1$ do art. $3^{\circ}$ da Lei da União de Facto operam igualmente mediante uma pura remissão para o regime do casamento ou da viuvez ${ }^{47}$; e

\footnotetext{
44 Tratando-se, além do mais, de pontos de regime relativos a matérias que os conviventes poderão não ter tido oportunidade de regular - já porque entretanto um deles faleceu, já porque se deu uma ruptura da sua relação.

45 Efectivamente, em caso de ruptura, a Lei da União de Facto limita-se a remeter para os arts. $1105^{\circ}$ e $1793^{\circ}$, relativos ao divórcio; e, em caso de morte, surge-nos também uma remissão para o regime dos direitos concedidos ao cônjuge sobrevivo no caso de se tratar de casa arrendada (o art. $5^{\circ}, \mathrm{n}^{\circ} 10$, da Lei da União de facto remete para o art. $1106^{\circ}$ do Código Civil), e, no caso de se tratar de casa própria, o extenso conjunto de efeitos predispostos nos $n^{\circ}$ s 1 a 9 do art. $5^{\circ}$ da Lei da União de Facto corresponde também, em alguma medida, às "atribuições preferenciais" fixadas no art. $2103^{\circ}$-A do Código Civil.

46 Assim os arts. $4^{\circ}$ e $5^{\circ}, n^{\circ} 10$, da Lei $n^{\circ} 7 / 2001$, de 11 de Maio (na redacção resultante da Lei $\mathrm{n}^{\circ}$ 23/2010, de 30 de Agosto)

${ }^{47}$ Remissão que hoje, após a Lei $\mathrm{n}^{\circ} 23 / 2010$, é feita sem qualquer reserva, mesmo quanto às prestações sociais previstas nas als. e), f) e g) - que operam agora automaticamente (como sucede em caso de casamento ou viuvez), e não dentro da lógica "alimentar" que parecia ser a opção da lei antes das alterações de 2010.
} 
o mesmo sucede em relação a outros direitos concedidos ao (ex-) companheiro, como o direito a indemnização por morte, nos termos do art. $496^{\circ}, \mathrm{n}^{\circ} 3$, do Código Civil ${ }^{48}$.

5. A conclusão fundamental que se retira deste brevíssimo percurso é pois, insistimos, a de que se estreitou substancialmente a distância entre o casamento e a união de facto, sobretudo em consequência do novo perfil do casamento que resulta das recentes alterações legislativas.

Este recuo no "perfil contratual" do casamento traduzir-se-á - sintetizando e recompondo de alguma forma as observações que aqui fomos deixando -, em primeiro lugar, numa perda de importância do "momento declarativo" (ou seja, do acto ou contrato de casamento) em confronto com o seu "momento executivo" (ou seja, o estado do casamento, a execução do projecto de comunhão de vida). É verdade que o Código Civil mantém ainda, como é aliás compreensível, uma extensa lista de possíveis causas de invalidade (ou inexistência) do casamento - por incapacidade ou "impedimento" matrimonial, por vício de forma, por divergência entre a vontade e a declaração ou vício da vontade relevantes. Simplesmente, sabemos que em matéria de casamento vale entre nós uma "regra de validade", expressa no art. $1627^{\text {a }}$ do Código Civil, pelo que a invalidade (ou inexistência) do casamento será, neste sentido, excepcional; por outro lado, os efeitos da invalidade do casamento acabam muitas vezes por poder ser neutralizados quer por força da sanação dessa invalidade ${ }^{49}$, quer mediante o funcionamento do instituto do casamento putativo ${ }^{50}$; além do mais, deve reconhecer-se que algumas das causas

\footnotetext{
48 De acordo com a nova redacção do preceito, introduzida com a Lei ${ }^{\circ}$ 23/2010.

49 Por confirmação, convalidação ou decurso do prazo de arguição da anulabilidade.

50 Previsto nos arts. $1647^{\circ}$ e $1648^{\circ}$ do Código Civil.
} 
de invalidade - estamos exactamente a pensar nos impedimentos matrimoniais - se fundam não tanto numa incapacidade relativa ao consentimento, mas sobretudo numa incapacidade relativa ao estado de casado51; por último, o que importa aqui sublinhar é que, esvaziadas as declarações negociais dos nubentes do seu conteúdo "de assunção de um vínculo" - vínculo este que hoje já nem existirá verdadeiramente, nem no plano das características e da garantia dos "deveres conjugais" nem sobretudo no da garantia de perdurabilidade do casamento -, a invocação da invalidade do casamento acaba por ter escassíssima importância prática, tendo em conta que os cônjuges poderão sempre, ou com grande facilidade, pôr termo ao casamento por via do divórcio ${ }^{52}$. Diremos pois que o velho paradigma matrimonial assente no contrato e nos seus possíveis vícios, com a consequente invalidade desse contrato, se encontra hoje, no quadro do novo perfil de casamento resultante sobretudo da Reforma de 2008, definitivamente comprometido. E a referida perda de importância do "momento declarativo" do casamento significará uma correlativa valorização do seu "momento executivo": mais que o contrato de casamento, e o compromisso ou a vinculação aí assumida, o que importa verdadeiramente é a continuada execução

51 Trata-se, pois, no seu fundamento, não de incapacidades para casar mas de incapacidades para "estar casado" - para assumir o estado de casado ou "executar" os comportamentos correspondentes a uma plena comunhão de vida. Circunstância que, aliás, se reflecte no próprio regime das anulabilidades daí resultantes, quer em relação aos prazos para a sua arguição quer em relação ao círculo de pessoas com legitimidade para essa arguição.

52 Ao que julgamos saber, supomos que as referidas causas de invalidade do casamento, sobretudo os designados "vícios do consentimento", acabam por, na realidade, ser pouco ou raramente invocados em juízo, não tendo pois, nesta perspectiva, grande interesse prático - ressalvada a declaração de nulidade do casamento católico, mas aí por razões específicas da lei canónica. Referimo-nos ao facto de a declaração de nulidade do casamento católico ser o único meio, de acordo com a lei canónica, de os cônjuges casados catolicamente obterem a cessação do casamento (fora a hipótese marginal de casamento rato e não consumado) e simultaneamente terem a possibilidade de vir a contrair um novo casamento católico. 
do projecto de comunhão de vida, nos termos em que os sujeitos o executarem e enquanto o executarem.

O referido recuo do perfil contratual do casamento - e esta é uma segunda observação conclusiva - faz-se sobretudo sentir, como é evidente, ao nível dos seus efeitos negociais ou directos. Os efeitos essenciais a que se dirigiria a vontade dos nubentes, mas que justamente os unidos de facto pretenderiam excluir - a assunção de um compromisso, dotado de um mínimo de garantias e sem a possibilidade de uma denúncia unilateral ad nutum -, tais efeitos não se descobrem hoje com facilidade no próprio casamento. Diremos pois que, no essencial, desapareceu a base do que era a diferença fundamental entre o casamento e a união de facto. É verdade que os unidos não querem vincular-se juridicamente; mas também é verdade que, hoje, o regime legal do casamento não proporciona nem permite aos nubentes uma vinculação jurídica clara, como tivemos oportunidade de expor.

Esbatida a base da diferença principal entre os dois institutos, afigura-se - esta é uma terceira observação - que deixou de haver fundamento para a recusa de uma aplicação analógica, à união de facto, de muitas normas do casamento que estabelecem efeitos indirectos ou laterais de diversa ordem. A ideia de que certas normas do casamento pressuporiam um dever conjugal, e nessa conformidade seriam insusceptíveis de se aplicar analogicamente à união de facto precisamente porque aqui os sujeitos não assumiriam quaisquer deveres ${ }^{53}$, parece, na realidade, desajustada do direito matrimonial

53 Tal argumento continua a ser usado para recusar, p. ex., a aplicação à união de facto do art $1691^{\circ}, \mathrm{n}^{\circ} 1$, al. c), do Código Civil (ao qual nos referimos já) ou da obrigação de alimentos subsequente ao divórcio (arts. $2016^{\circ}$ e $2016^{\circ}$-A do Código Civil). Quanto a este segundo caso, reconhecemos que a orientação firme dos nossos tribunais (v., p. ex., o Acórdão do STJ de 4/2/1992, Colectânea de Jurisprudência, Acórdãos do Supremo Tribunal de Justiça, 1992, Tomo V, p. 89) tem sido, efectivamente, no sentido de negar aos ex-conviventes, após a ruptura da sua união, um direito a alimentos análogo ao estabelecido nos arts. $2016^{\circ}$ e $2016^{\circ}$-A - sobretudo com fundamento na ideia de que o dever de alimentos pós-divórcio representaria 
actual, no âmbito do qual os deveres conjugais se apresentam de alguma forma, repetimos, como um puro quadro "formal".

6. E à (quase) identidade jurídica entre o casamento e a união de facto devemos acrecentar, de igual modo, a sua (quase) identidade no plano sociológico - muito exactamente, no plano das funções desempenhadas por um e outro institutos. Efectivamente, a análise sociológica, ou económico-sociológica, vem mostrando que as funções ou vantagens normalmente associadas ao casamento - nos dias de hoje, fundamentalmente a "mútua gratificação afectiva" dos cônjuges, a partilha de recursos e sacrifícios através da constituição de um núcleo de economia comum, a educação, socialização ou "aculturação" dos filhos (ou da geração subsequente) -, tais funções ou vantagens são igualmente asseguradas, com o mesmo grau de eficiência, pela união de facto. O casamento deixa pois de ser necessário, nos planos social, afectivo, cultural ou económico; e tal sensação de desnecessidade, estamos em crer, é em geral partilhada pelas pessoas ${ }^{54}$, que tendem a aceitar a união de facto como uma relação equivalente ou idêntica ao casamento - só subsistindo uma larga maioria de casamentos ${ }^{55}$, supomos nós, por muitas vezes se

tão simplesmente um prolongamento do dever conjugal de assistência, o qual, justamente, não existiria na relação convivencial entre os unidos de facto. Ora, ainda que fosse essa a única ratio da obrigação alimentar entre ex-cônjuges - o que evidentemente é discutível -, o que sucede é que, tal como expomos no texto, os deveres conjugais, no actual contexto normativo, são mais um quadro "formal" do que propriamente deveres com existência efectiva.

${ }^{54} \mathrm{Em}$ sentido diverso, aparentemente, GUILHerme DE Oliveira, Notas, cit., p. 140 (afirmando que "a sociedade (...) dá preferência ao casamento como modelo jurídico de regulação da vida íntima"). Mas - concedemos - é claro que estamos aqui a lidar com realidades insusceptíveis de um conhecimento preciso, e muito menos de "quantificação".

55 Mas mesmo estes, segundo parece, muitas vezes após o decurso de um certo tempo de união de facto - apresentando-se o casamento, pois, como uma espécie de "ritual de confirmação" de uma relação que já existia. 
tratar de um hábito adquirido e de, pelo menos em certos meios, haver uma pressão social e religios $a^{56}$ nessa direcção.

7. A identidade ou analogia fundamental que reconhecemos existir entre o casamento e a união de facto, sobretudo após a alteração de paradigma do casamento (e do divórcio) resultante da Lei $\mathrm{n}^{\circ}$ 61/2008, esbarra ainda hoje, contudo, com a atribuição de escassíssimos efeitos legais à união de facto ${ }^{57}$ - subsistindo diversas matérias em que é claro o intuito, por parte da lei, de tratar de forma diversa o casamento e a união de facto, não sendo pois admissível, perante esse claro intuito, proceder-se a qualquer extensão analógica do regime do casamento ${ }^{58}$.

Ora, é indiscutível que a diferença que sobressai de forma mais nítida tem a ver com os efeitos sucessórios do casamento e da união de facto. A um fortíssimo estatuto sucessório do cônjuge sobrevivo - que é não apenas herdeiro legítimo (e numa posição qualificada em face dos demais herdeiros legítimos ${ }^{59}$ ) mas também herdeiro legitimário, como é sabido - contrapõe-se um estatuto sucessório do companheiro sobrevivo praticamente vazio: o companheiro so-

\footnotetext{
56 Obviamente que, para o direito canónico, o casamento constitui um sacramento, pelo que, aí, há uma diferença radical entre o acto de casamento, regularmente celebrado perante um ministro do respectivo culto, e a mera situação de facto de convivência more uxorio. Simplesmente, os valores ou interesses que estão subjacentes à "regularidade" apenas do casamento - não da união de facto - são completamente estranhos ao direito civil, que lida com interesses de ordem totalmente diversa.

57 Para um levantamento de algumas matérias que ainda não foram consideradas expressamente pela lei, e que, para o autor, deveriam merecer a sua atenção, v. GUILHERME DE OlIVEIRA, Notas, cit., p. 150 e ss.

58 Tratar-se-á, em tais casos, de "lacunas aparentes": não há qualquer ausência de uma "regulamentação exigida ou postulada pela ordem jurídica global", ou de "resposta, [no sistema], a uma questão jurídica" (V. J. BAPTISTA MACHADO, Introdução ao Direito e ao Discurso Legitimador, Coimbra, 1990, p. 194), porquanto a lei, ao omitir o tratamento específico de tais matérias, quis, de modo claro, dar-lhe o tratamento que resulta das regras gerais.

59 Nos termos do art. $2139, \mathrm{n}^{\circ} 1$, a quota do cônjuge não pode ser inferior a um quarto da herança.
} 
brevivo não é herdeiro do falecido, limitando-se a lei a conceder-lhe um direito a exigir alimentos da herança do falecido ${ }^{60}$, direito este que, aliás, a lei já atribuía ao cônjuge ${ }^{61}$. E a diferença é de tal forma marcante - em face da progressiva indiferenciação do casamento e da união de facto na generalidade das matérias, e em particular nesta área da protecção do sobrevivo em caso de morte - que pode mesmo afirmar-se que hoje o casamento se apresenta, nesta perspectiva, como ... um (quase) contrato sucessório, no sentido de que o "grande efeito", o efeito mais significativo que os sujeitos vão obter, optando pelo casamento em lugar da união de facto, é precisamente esse efeito sucessório ${ }^{62}$ !

Supomos que tal diversidade de tratamento - excessiva, na realidade, tendo em conta aquela indiferenciação ou aproximação - deve ser objecto de atenção pelo legislador ${ }^{63}$, quer mediante a atribuição ao companheiro sobrevivo de uma posição sucessória "razoável", quer sobretudo, e inversamente, mediante a depreciação ou o enfraquecimento do estatuto sucessório deste cônjuge sobrevivo, pelo menos na parte que se refere à sua qualidade de herdeiro legitimário.

Em relação à posição sucessória do unido de facto sobrevivo, cremos que se justificaria que pudesse integrar a escala de suces-

60 Direito a alimentos condicionado, nos termos gerais, ao duplo requisito da necessidade de alimentos por parte do alimentando e da possibilidade de os prestar por parte do alimentador (arts. $2003^{\circ}, 2004^{\circ}$ e $2013^{\circ}$ do Código Civil).

${ }^{61}$ Referimo-nos aqui ao apanágio do cônjuge sobrevivo (art. $2018^{\circ}$ do Código Civil) - direito que, convenhamos, se encontra hoje praticamente destituído de importância prática -, ao qual já anteriormente aludimos.

${ }^{62}$ Estamos aqui a pensar, fundamentalmente, na qualidade de herdeiro legitimário.

63 Mais, aliás, que outros pontos apontados pelos autores (como a eventual necessidade de um registo da união - que nos parece que nunca deveria além de uma função probatória -, ou a regulação dos regimes de bens, dos poderes de administração de bens e da responsabilidade por dívidas - que são matérias basicamente "técnicas", de simples arrumação ou organização, e nas quais podem já, de resto, operar analogias). 
síveis na sucessão legítima, porventura numa posição inferior à do cônjuge, descendentes e ascendentes ${ }^{64}$.

Em relação à posição sucessória do cônjuge sobrevivo, e admitindo não ser este o espaço próprio para o tratamento desenvolvido do problema - que, de resto, ultrapassa a perspectiva do mero confronto com a união de facto -, alinhamos aqui, de modo sumário, algumas razões que julgamos deporem a favor dessa depreciação.

Em primeiro lugar, e como se viu, o casamento é, por um lado, cada vez menos "vinculativo" no plano dos efeitos pessoais e, por outro lado, cada vez mais precário, dada a progressiva facilitação do divórcio. Diríamos pois que o casamento hoje vale pouco - vincula pouco, e pode cessar facilmente. Parece portanto que este actual regime "familiar" do casamento se acha um pouco desajustado do seu regime sucessório, o qual terá sido pensado, pelo contrário, para o velho casamento perpétuo e de forte carga vinculativa. De alguma forma se diria, nesta sequência, que o casamento conseguiria, por via sucessória e portanto após o seu termo, uma vinculatividade e uma perpetuidade que não teria normalmente durante a sua vigência.

Em segundo lugar, também não nos parece colher o argumento de que, precisamente por ser o casamento cada vez mais precário, deve justamente ser mais valorizado o casamento que consegue sobreviver até à morte de um dos cônjuges ${ }^{65}$. E não nos parece colher semelhante argumento porquanto não pode garantir-se que o casamento iria perdurar por muito mais tempo; de resto, o casamento

64 Vai neste sentido, note-se, o Código Civil de Macau (arts. $1983^{\circ}$ e $1985^{\circ}$ ). Repare-se, por outro lado, que a posição sucessória inferior do unido em face do cônjuge sobrevivo é, em parte, aparente, pois que resulta logo da desconsideração da união de facto adulterina.

65 A este argumento aludem PAULA T. VÍTOR/ROSA C. MARTINS, New marriage, old succession? The influence of the new conceptions of marriage in the position of the surviving spouse, in "Essays in honour of Penelope Agallopoulou", Atenas, 2011, p. 1473. Aliás, ao que julgamos saber, tal argumento terá pesado - no âmbito dos trabalhos da Comissão de Reforma do Código Civil que preparou a Reforma de 1977 - no sentido da consagração do actual regime sucessório. 
pode ter durado pouco, se a morte se deu pouco tempo após o casamento; e parece artificial, de qualquer modo, essa distinção entre casamentos "fortes" e casamentos "fracos", a ponto de fundamentar uma tal diferenciação de regimes sucessórios.

Em terceiro lugar, não vemos que as exigências de solidarieda$d e^{66}$ em favor do cônjuge sobrevivo, as quais estarão na base da sua sólida posição sucessória, sobretudo enquanto herdeiro legitimário, justifiquem tão elevado grau de protecção sucessória - mais elevado, como sabemos, que a protecção reservada aos próprios descendentes. Visto globalmente o sistema de protecção do cônjuge sobrevivo, o qual inclui prestações de diversa ordem ${ }^{67}$, não vemos que haja uma necessidade estrita de reservar para o cônjuge, de forma imperativa, uma parcela da herança ${ }^{68}$.

E a própria ideia de que aquela exigência de solidariedade assentaria num específico dever conjugal (o dever de assistência), cujo cumprimento não deve ser interrompido só porque a morte interrompeu (contra a vontade dos cônjuges) o casamento, também parece desfasada da actual configuração dos "deveres" conjugais, tal como julgamos deverem ser entendidos, e da actual precariedade e falibilidade do casamento: não era seguro que o casamento perdurasse por tempo indeterminado, e que portanto o cônjuge (que agora faleceu) continuasse, por tempo indeterminado, a cumprir normalmente o seu dever de assistência; e, de qualquer modo, a transmissão here-

66 Sobre as duas preocupações possíveis subjacentes à designação legal dos sucessíveis (sobretudo dos legitimários) - a solidariedade (ou cuidado) e a "contribuição" (ou compensação pelos serviços prestados pelo agora beneficiário), v. a análise cuidada de PAUla T. VítOR/ROSA C. MARTINS, cit., ps. 1469 ss.

${ }^{67}$ Alimentares, relativas à casa de morada, resultantes dos regimes da segurança social, etc.

68 Curiosamente, o Código Civil de Macau, muito moldado no nosso Código Civil, mantendo embora a posição de legitimário do cônjuge sobrevivo (art. 1995º, permite todavia que os cônjuges renunciem reciprocamente à sua qualidade de herdeiros legitimários, devendo fazê-lo em "convenção matrimonial" (antenupcial ou "pós-nupcial" - arts. $1971^{\circ}$ e $1978^{\circ}$ ). 
ditária ultrapassa em muito, no seu objecto, a lógica e propósitos "alimentares" e assistenciais do referido dever conjugal. 